\title{
NASA Common Research Model Test Envelope Extension with Active Sting Damping at NTF
}

\author{
Melissa B. Rivers ${ }^{1}$ \\ NASA Langley Research Center, Hampton, VA 23681 \\ S. Balakrishna ${ }^{2}$ \\ ViGYAN Inc., Hampton, VA 23681
}

\begin{abstract}
The NASA Common Research Model (CRM) high Reynolds number transonic wind tunnel testing program was established to generate an experimental database for applied Computational Fluid Dynamics (CFD) validation studies. During transonic wind tunnel tests, the CRM encounters large sting vibrations when the angle of attack approaches the second pitching moment break, which can sometimes become divergent. CRM transonic test data analysis suggests that sting divergent oscillations are related to negative net sting damping episodes associated with flow separation instability. The National Transonic Facility (NTF) has been addressing remedies to extend polar testing up to and beyond the second pitching moment break point of the test articles using an active piezoceramic damper system for both ambient and cryogenic temperatures. This paper reviews CRM test results to gain understanding of sting dynamics with a simple model describing the mechanics of a sting-model system and presents the performance of the damper under cryogenic conditions.
\end{abstract}

\section{Nomenclature}

$A \quad=$ aerodynamic loads at balance center

$\mathrm{BMC} \quad=$ balance moment center

$\mathrm{c}$, cbar $\quad=$ mean aerodynamic chord

$C P \quad=$ center of pressure

$C_{B} \quad=$ buffet coefficient

$\mathrm{C}_{\mathrm{m} \dot{\alpha}}+\mathrm{C}_{\mathrm{mq}}=$ Aerodynamic damping

$\mathrm{C}_{\mathrm{D}} \quad=$ Drag coefficient

$\mathrm{C}_{\mathrm{L}} \quad=$ Lift coefficient

$C_{\mathrm{m}} \quad=$ Pitching moment coefficient

$\mathrm{C}_{\mathrm{N}} \quad=$ Normal force coefficient

$\mathrm{E} \quad=$ Young's Modulus

$f \quad=$ sting friction damping

I $\quad=$ cantilever sting model system inertia

$k=$ sting bending stiffness, $\Sigma / \theta$

$k_{g} \quad=$ damper feedback gain

$k_{m} \quad=$ sting bending angle/pitching moment

$k_{N} \quad=$ sting bending angle/normal force

$\mathrm{M}_{\infty} \quad=$ Mach number

$\mathrm{NF} \quad=$ normal force at balance center

$\mathrm{PM}=$ pitching moment at balance center

$q_{\infty} \quad=$ dynamic pressure

$\operatorname{Re}_{\mathrm{c}} \quad=$ Reynolds number based on mean aerodynamic chord

$\Sigma \quad=$ Sting Moment

\footnotetext{
${ }^{1}$ Research Engineer, Configuration Aerodynamics Branch, Mail Stop 267, Senior Member AIAA.

${ }^{2}$ ViGYAN Inc., Hampton, VA, Non-Member.
} 


$\begin{array}{ll}\Sigma /(\partial \theta / \partial t) & =\text { Sting Moment due to } \theta \text { rate } \\ \mathrm{t} & =\text { time, } \mathrm{s} \\ \mathrm{T}_{\mathrm{t}} & =\text { tunnel temperature } \\ w(x) & =\text { deflection of cantilever } \\ \mathrm{WB} & =\text { wing/body configuration } \\ \mathrm{WBTi} & =\text { wing/body/tail=i deg incidence configuration } \\ \mathrm{x} & =\text { distance } \\ \alpha & =\text { model angle of attack, deg } \\ \theta & =\text { sting bending angle at balance, deg } \\ \mu(\mathrm{x}) & =\text { mass distribution of sting }\end{array}$

\section{Introduction}

$\mathrm{T}$ rasonic wind tunnel tests of scaled models with long stings usually have issues with model support system dynamics due to buffet and other potential flow instabilities at high angles of attack. Model test angle of attack range is cut short many times due to excessive and unsafe sting dynamics. Many efforts have been made historically to suppress sting vibrations by increasing the sting system damping either by passive or active methods ${ }^{1-}$ 5

The NASA LaRC National Transonic Facility (NTF) has frequently encountered issues of model dynamics during the high Reynolds number, high angle of attack transonic testing of civilian and military transport models ${ }^{5,6}$. Two types of sting/model dynamics have been observed beyond the first pitching moment break in NTF tests. The first type of sting dynamics is severe but stable buffeting. The second type of dynamics is violently diverging sting oscillations in the first sting mode. To mitigate these, NTF has developed active piezoceramic actuator based dampers for several test articles including the Pathfinder I, Crew Launch Vehicle, and Common Research Model $(\mathrm{CRM})^{4,5}$.

The CRM was established to generate an experimental database for CFD validation studies ${ }^{7}$. In order to validate the CFD codes for large angles of attack, an aerodynamic force-moment-pressure-wing root strain database is required up to and beyond the second pitching moment break point. Part of this database enables gaining insight into the mechanics of sting-model dynamics and instability. This paper presents analysis of the CRM data from a sting dynamics point of view. This paper also presents the performance of an actively heated damper at cryogenic conditions and damper effectiveness in extending the testing range to higher angles of attack.

\section{NASA Common Research Model}

The model used in the three wind tunnel tests discussed in this paper is the NASA Common Research Model $(\mathrm{CRM})^{7}$, which was initially designed to be the basis for the fourth AIAA CFD Drag Prediction Workshop (DPWIV) $)^{8}$. This configuration consists of a contemporary supercritical transonic wing and a fuselage that is representative of a wide-body commercial transport aircraft. The CRM is designed for a cruise Mach number of 0.85 with a corresponding design lift coefficient of 0.5 . The aspect ratio is 9.0 , the leading edge sweep angle is $35^{\circ}$, the wing reference area $\mathrm{S}$ is $3.01 \mathrm{ft}^{2}$, the wing span $\mathrm{b}$ is 62.46 inches, and the mean aerodynamic chord $\mathrm{c}$ is 7.45 inches. The model moment reference center is located 35.8 inches back from the fuselage nose and 2.04 inches below the fuselage centerline. Simple flow through engine nacelles can be mounted on the model; however, results from this configuration are not discussed herein. The CRM is instrumented for force and moment measurements, wing static pressures, wing-root bending moments and wing dynamic pressures. The wing pressure distributions are measured on both the port and starboard wings using 291 pressure orifices located in 9 span-wise wing stations $(\mathrm{h}=0.131$, $0.201,0.283,0.397,0.502,0.603,0.727,0.846$, and 0.950 ). The wing-root bending is measured using half bridges on both wings and the dynamic pressures are measured on the port wing using Kulite sensors, which are located at approximately $70 \%$ span. The model is mounted in the wind tunnel using a blade sting arrangement as seen in Fig. 1, which provides the main topic for this paper. The CRM was tested in the NASA Langley NTF (Test 197) and NASA Ames 11-ft Transonic Wind Tunnel (Test 216) in 2010 with an earlier generation active damper and was tested again in the NASA Langley NTF in the spring of 2013 (Test 215) with the latest generation active damper. 


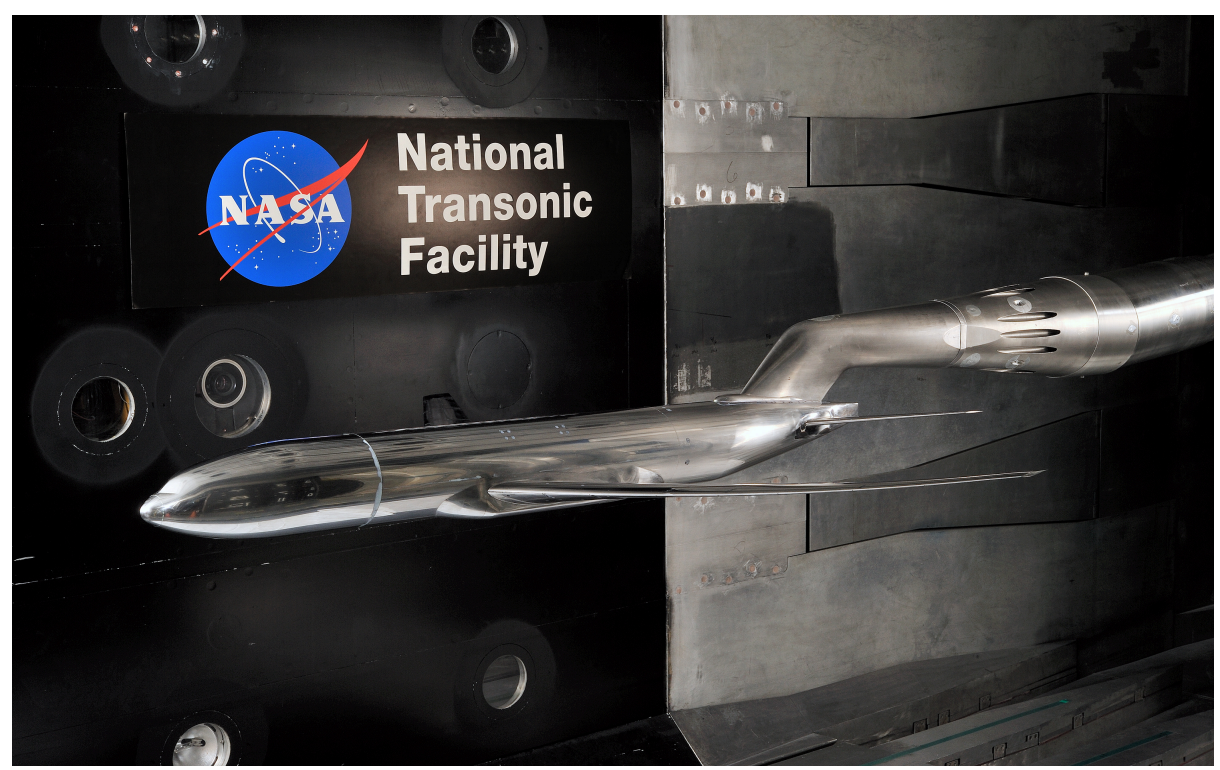

Figure 1. CRM mounted in the NTF.

Figures 2 and 3 show the lift and pitching moment curves from these three wind tunnel tests for the wing/body (WB) and wing/body/tail $=0 \mathrm{deg}$ (WBT0) configurations, respectively. Figure 2 shows that the highest angle of attack for the WB configuration at $\mathrm{M}=0.85$ and $\mathrm{Re}_{\mathrm{c}}=5$ million was obtained during NTF Test 215. The highest angle of attack for the WBT0 configuration at $\mathrm{M}=0.85$ and $\mathrm{Re}_{\mathrm{c}}=5$ million was obtained during the Ames 11 -ft Test 216 with NTF Test 215 showing a small improvement over NTF Test 197, as shown in Fig. 3.

\begin{tabular}{|c|c|c|c|c|c|}
\hline & Facility & Run & $\mathrm{M}_{\infty}$ & $\operatorname{Re}_{\mathrm{c}}, 10^{6}$ & $\mathrm{q}_{\infty}, \mathrm{psf}$ \\
\hline & NTF Test 197 & 44. & 0.85 & 4.99 & 1386. \\
\hline ם & Ames $11-\mathrm{ft}$ Test 216 & 126. & 0.85 & 5.00 & 1312 . \\
\hline$\odot$ & NTF Test 215 & 43. & 0.85 & 4.99 & 1387. \\
\hline
\end{tabular}
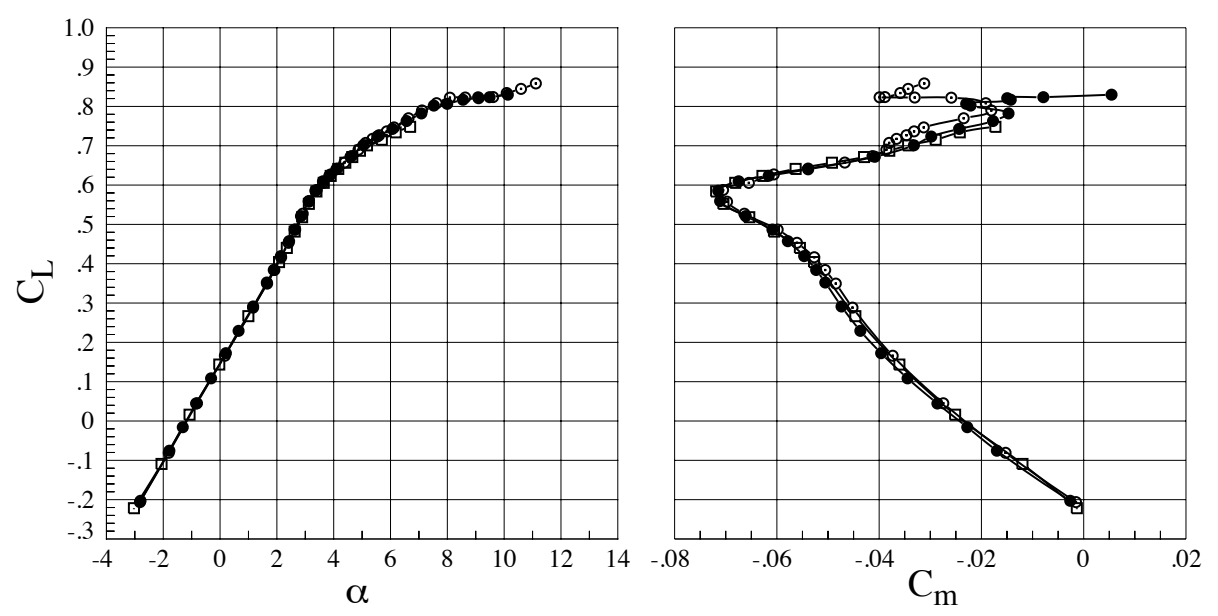

Figure 2. Lift and pitching moment for $W B$ configuration, $M=0.85, R_{c}=5$ million. 

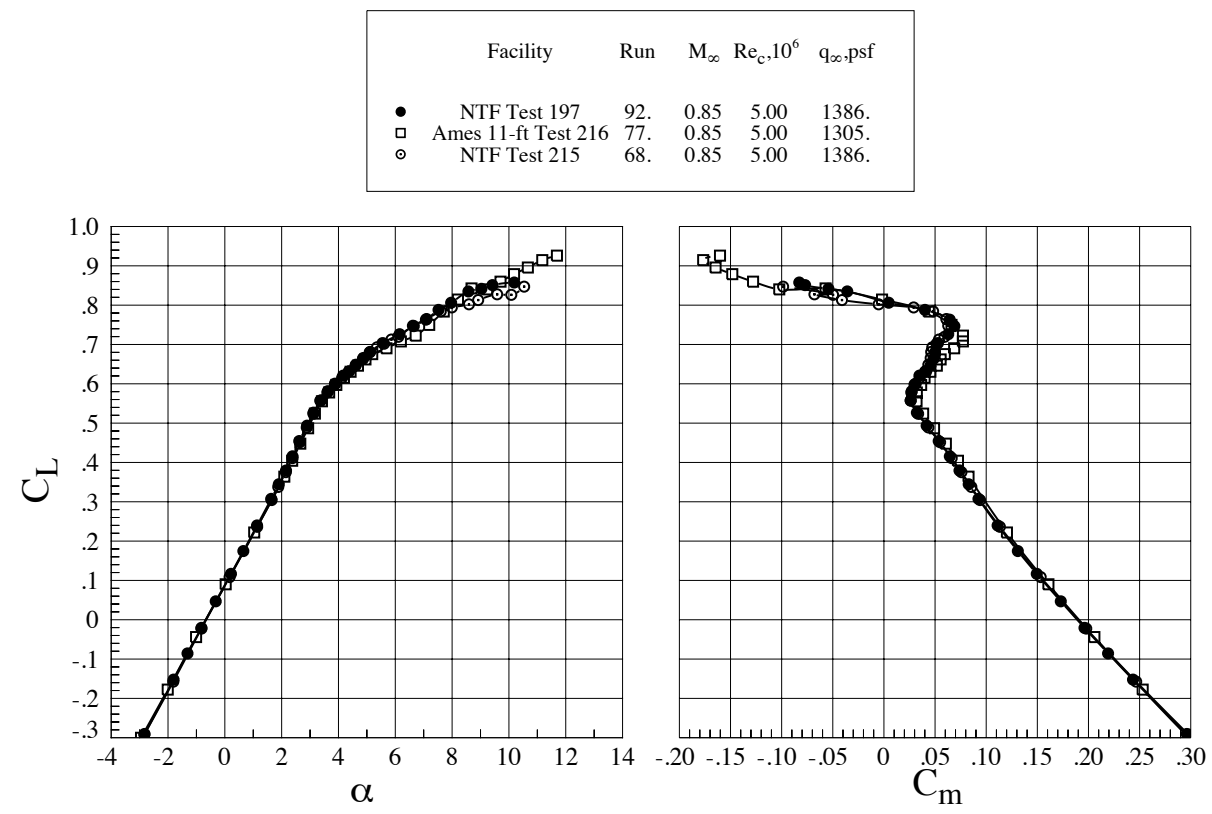

Figure 3. Lift and pitching moment for the WBT0 configuration, $M=0.85, \operatorname{Re}_{c}=5$ million.

In order to ensure a consistent and repeatable transition from laminar to turbulent flow at low Reynolds numbers and to support the goal of the wind tunnel data being used for CFD validation purposes, it was important to apply a proven and reliable method to fix boundary layer transition on the model. Trip dots measuring 0.05 inches in diameter and spaced 0.1 inches apart (center to center) were used for the three wind tunnel tests on the CRM. For a chord Reynolds number of 5 million, a trip dot height of 0.0035 inches was used from the SOB (side of body) to the yehudi break, 0.003 inches was used from the yehudi break to the wing tip. These trip dots were installed at $10 \%$ chord on the upper and lower surface of both the port and starboard wings. Trip dots with a height of 0.004 inches were applied one inch aft of the nose of the fuselage and left on for the entire test. When the nacelles were on the model, 0.003 inches trip dots were located 0.43 inches back from the leading edge on the outer and inner surfaces. Finally, when the tails were on the model, trip dots were located at $10 \%$ chord on both the upper and lower surfaces and measured 0.003 inches in height.

Several runs were performed with free transition at low Reynolds numbers to demonstrate the effect adding trip has on the data. When trip is added to the model to fix the transition point, the result is earlier transition from laminar to turbulent flow. This earlier transition results in a thicker boundary layer over the rear of the wing, causing an effective decambering that induces the lift loss, more positive pitching moment and drag increases due to higher turbulence as seen in Fig. 4. 

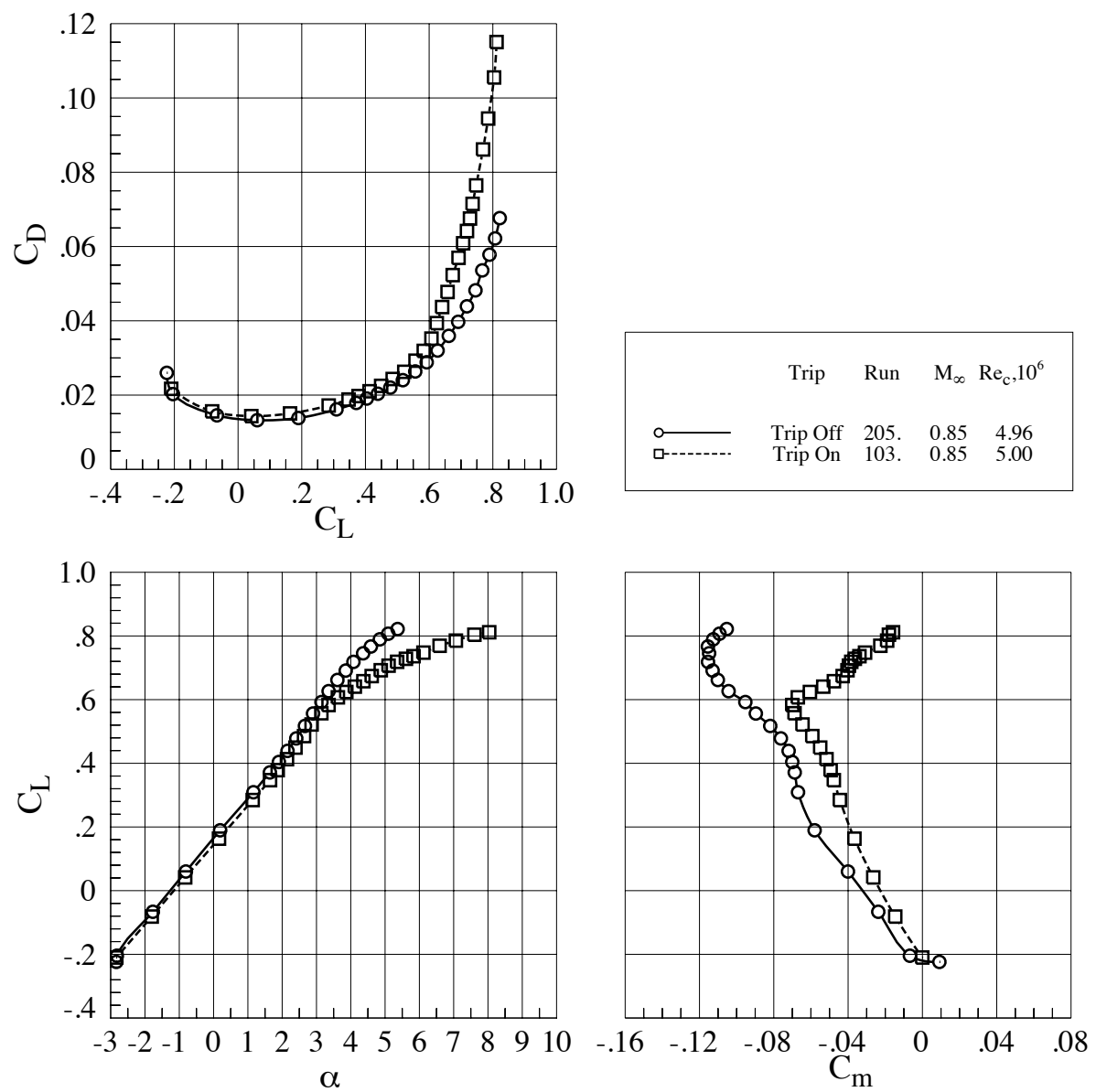

Figure 4. Lift, pitching moment and drag for trip on versus trip off, WB configuration, $M=0.85$, $\operatorname{Re}_{\mathbf{c}}=\mathbf{5}$ million.

\section{Modeling Sting Bending Dynamics}

Figure 5 shows typical CRM balance raw pitching moment and normal force as a function of angle of attack for two different runs for two different configurations at a Reynolds number of 5 million and a Mach number of 0.85 . This raw data is taken at the model moment center with temperature compensation and interaction tares applied. Plot (a) show typical first and second pitching moment breaks, which vary with test conditions, while plot (b) shows the corresponding normal force break points. A study of pitching moment as a function $\alpha$ shows that $\partial \mathrm{PM} / \partial \alpha$ has both positive and negative gradients which influence sting dynamics. 


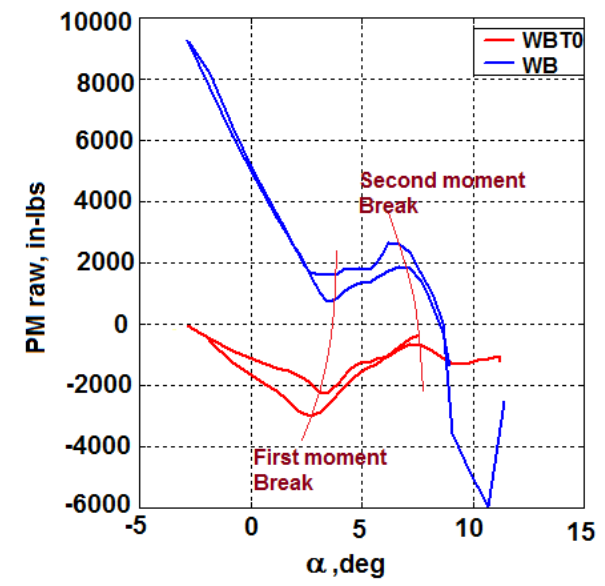

(a)

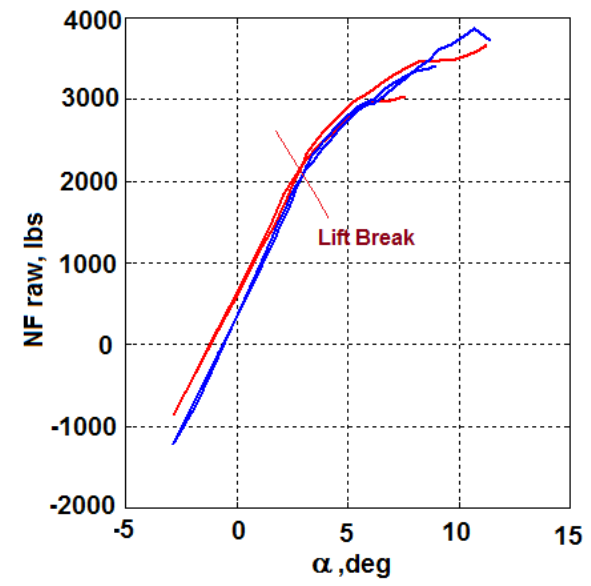

(b)

Figure 5. CRM pitching moment and normal force break points, $M=0.85, R_{c}=5$ million.

Figure 6 shows the buffet onset angle of attack determined from normalized wing root wideband ' $r m s$ ' strain $\mathrm{C}_{\mathrm{B}}$ from continuous sweep polars. Plot (a) shows $C_{B}$ as a function of angle of attack for $M=0.85$. Buffeting starts at the first pitching moment break ${ }^{9}$. Buffet is a forcing function for the sting support system. Figure 6 plot (b) shows buffet boundary as a function of Mach number and Reynolds number. Both figures 5 and 6 show that moment break point angles of attack continually vary with Mach number and Reynolds number.

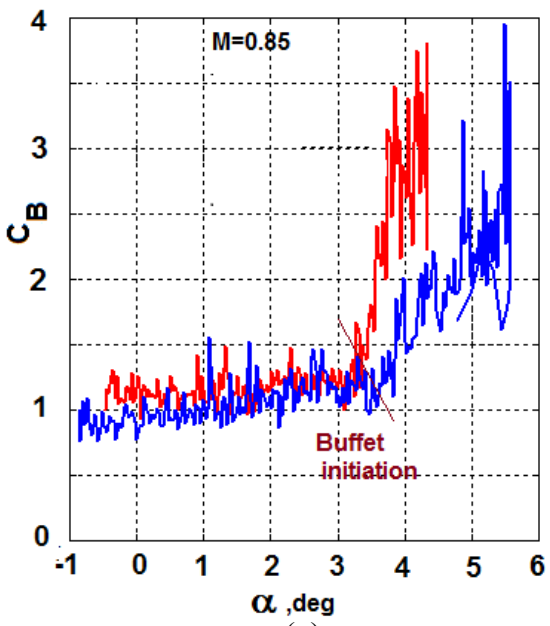

(a)

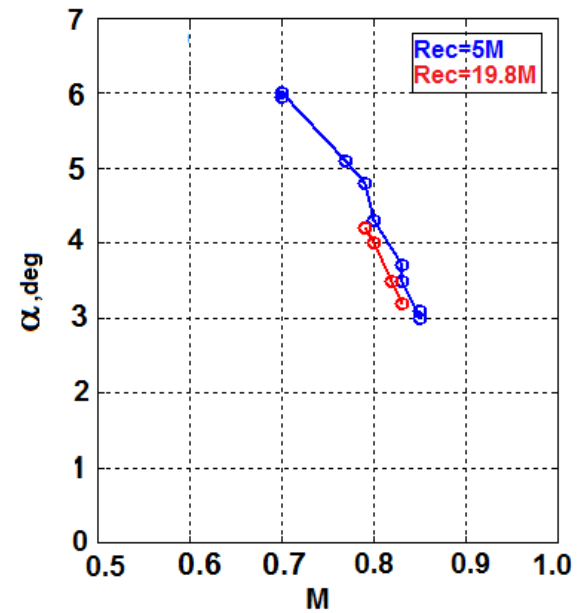

(b)

Figure 6. CRM buffet initiation and buffet boundary for WB configuration, $M=0.85$.

Unstable sting dynamics in transonic tunnels is usually dominated by the first Eigenmode of the cantilever sting ${ }^{4-6}$. Hence we look at the sting dynamics as a sting mechanics/stability problem of the first bending mode. A cantilever sting model support system is shown in Fig. 7. Figure 8 shows the relationship between the balance moment center and the model center of pressure. 


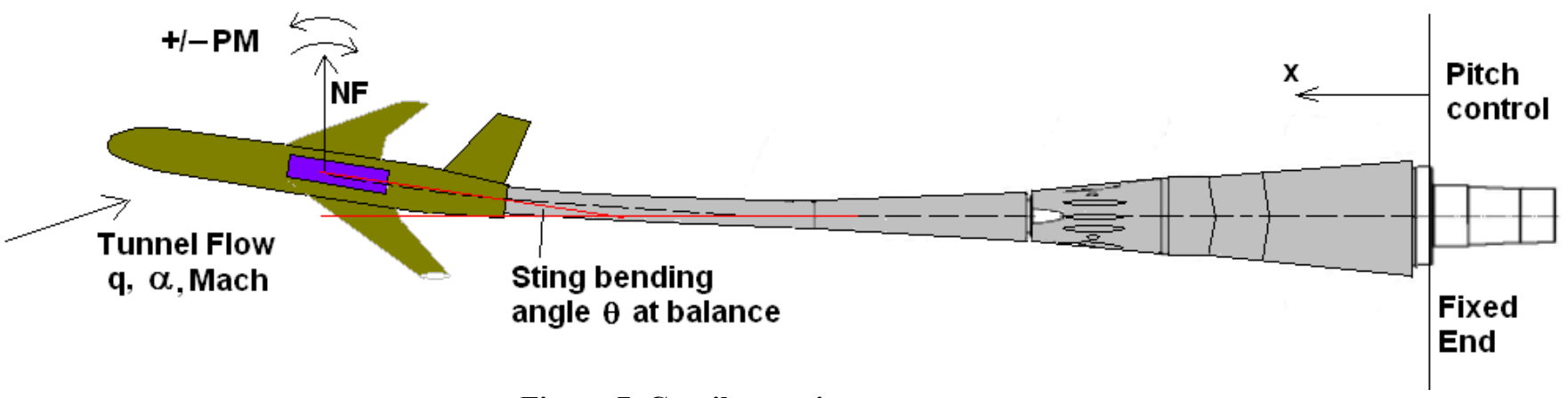

Figure 7. Cantilever sting system.

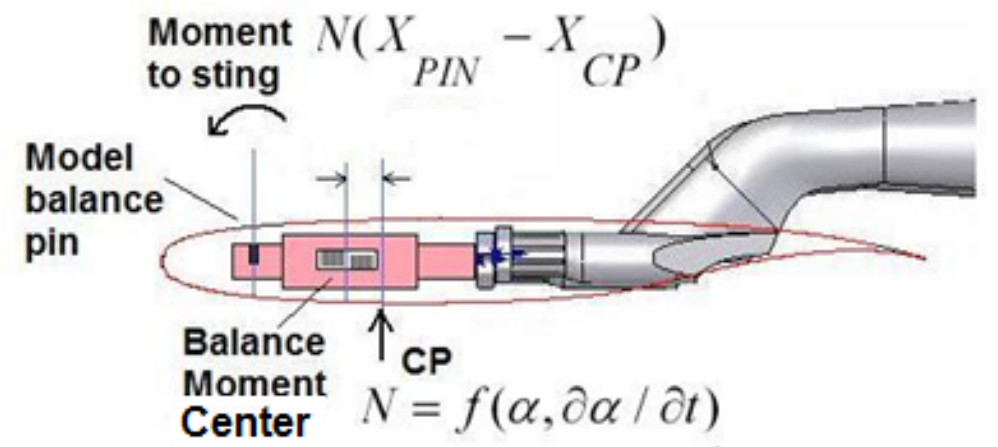

Figure 8. Reference points for the balance and sting system, not to scale.

The following equations provide a simple representation of the sting dynamics in a wind tunnel model under flow conditions. Eq. (1) describes spatial and temporal dynamics of a beam under load using the classical EulerBernoulli Beam Equation and its modification via the Euler-Lagrange identity. Term $\Sigma$ is the moment acting on the sting due to aerodynamic loading. Note that $\theta$ is the sting bending deflection angle at the BMC, referred to unloaded sting axis. It does not refer to pitch angle.

$$
E I \frac{\partial^{4} w}{\partial x^{4}}=-\mu \frac{\partial^{2} w}{\partial t^{2}}+A ; \theta=\frac{\int \Sigma_{x} x d x}{E I}
$$

By invoking the proper boundary conditions in Eq. (1) at both ends of the cantilever in the pitch axis and treating it as a simple single degree of freedom longitudinal system, we arrive at the moment equation, Eq. (2), which accounts for the effect of aerodynamic loads on the sting as a sting moment $\Sigma$ acting at the BMC.

$$
I \frac{d^{2} \theta}{d t^{2}}+f \frac{d \theta}{d t}+k \theta-\frac{\Sigma}{\partial \theta / \partial t} \frac{d \theta}{d t}-\frac{\partial \Sigma}{\partial \theta} \theta=0
$$

CRM aerodynamic normal force and pitching moment control the sting bending angle and sting moment $\Sigma$. Eq.(3) provides the experimentally determined relation between balance loads and sting bending angle.

$$
\theta=k_{n} N F(\alpha, \dot{\alpha})+k_{m} P M(\alpha, \dot{\alpha})
$$

The sting dynamics can be looked upon as a classical second order system with model aerodynamics contributing to damping and stiffness as in Eq.(4).

$$
I \frac{d^{2} \theta}{d t^{2}}+\frac{d \theta}{d t}(f-\Sigma /(\partial \theta / \partial t))+\theta(k-\partial \Sigma / \partial \theta)=0
$$


Eq. (4) ignores model-balance modes and other sting degrees of freedom, since their presence is not dominant in the unstable sting dynamic conditions. Since the sting bending angle $\theta$ is a direct function of angle of attack $\alpha$, the damping term $(f-\Sigma /(\partial \theta / \partial t))$ describes the role of the aerodynamic damping derivative from the wing on sting dynamics. The final term of Eq. (4), $(k-\partial \Sigma / \partial \theta)$, represents the static sting divergence identity where the lift slope and sting stiffness contribute to the sting static stability and controls the natural frequency of the sting system. The lift to $\theta$ relation is established by this expression.

\section{CRM Sting Pitch Dynamics and Aerodynamic Damping}

If the sting damping term in Eq. (4) is a large positive in a polar sweep, all pitch angle disturbances caused by unsteady flow are quickly annulled, yielding steady state response relating normal force to $\theta$. If sting damping is a small positive, there will be large sting vibration responses during a polar sweep due to disturbances after buffet initiation. If net damping becomes negative, the sting system will show divergent oscillations. Sting divergent oscillation events suggested by Eq. (4) have occurred in CRM tests at high Reynolds numbers near the second pitching moment break. One such divergent event from a CRM polar is illustrated in Figure 9 as five plots, for Mach $=0.85$ and $\mathrm{Re}_{\mathrm{c}}=19.8$ million.

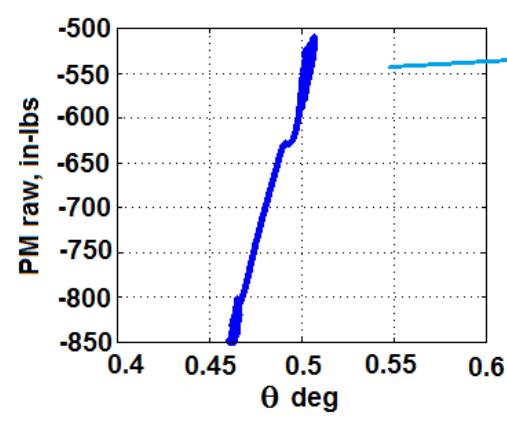

(a)

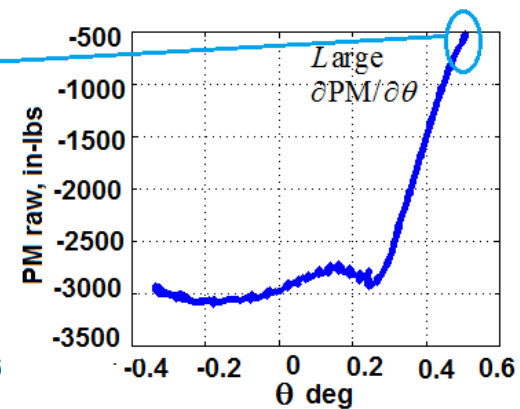

(b)

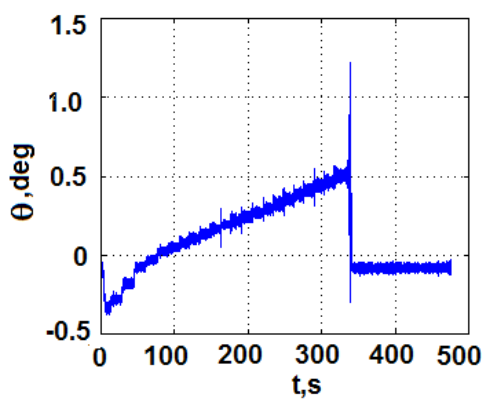

(d)

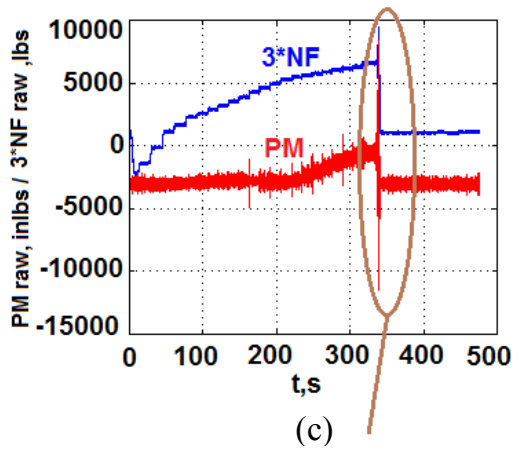

(c)

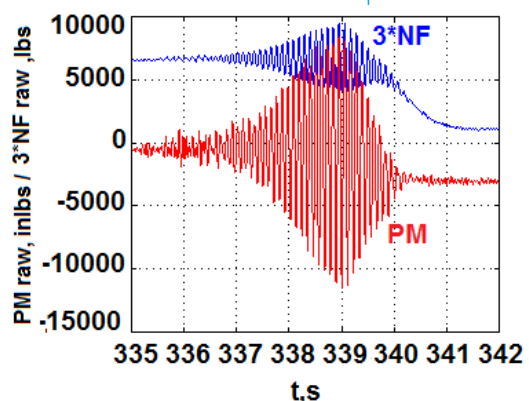

(e)

Figure 9. $C R M$ divergent sting oscillations, $W B$ configuration, $M=0.85, \operatorname{Re}_{c}=19.8 \mathrm{million}, T_{t}=-250^{\circ} \mathrm{F}$.

Figure 9 illustrates the events in a cold temperature, low dynamic pressure polar ending in divergent sting oscillations for the WB configuration at an angle of attack of approximately 3.5 degrees. Plots (a) and (b) show the wideband raw pitching moment PM vs $\theta$. A large positive gradient can be seen when divergent oscillations begin. Plot (c) shows the NF and PM during the polar which ends with divergent oscillations of the sting. Plot (d) shows the sting angle $\theta$ as function of time. Angle $\theta$ is initially linear and stable during the polar. At about $\theta=0.5$ degrees, divergent sting oscillations are seen. This is due to net negative damping for the sting. Once sting oscillations are initiated, $\theta$ has a peak-to-peak amplitude of 1.6 degrees. Plot (e) shows an enlarged time scale for NF and PM time events when the polar approaches the second pitching moment break. Normal force and pitching moment peak-topeak variations have exponentially diverged and reached approximately $1800 \mathrm{lbs} \& 18000 \mathrm{in}-\mathrm{lbs}$, respectively, in a short time of two seconds. These loads are beyond the balance dynamic load limits and the polar was stopped.

Since the frequency of the sting oscillations observed for the CRM for all divergent cases is the same as the unloaded sting first mode frequency of $10.1 \mathrm{~Hz}$, the term $\theta(k-\partial \Sigma / \partial \theta)$ of Eq. (4) is unlikely to be the cause of the divergent response. This term controls sting natural frequency. The damping term ( $\mathrm{f}-\Sigma(\partial \theta / \partial t)$ ) of Eq. (4) can 
only become negative if the aerodynamic pitch damping due to angle of attack rate is a large positive. The pitch dynamic derivative damping term $C m \dot{\alpha}$ is the likely contributor to the negative sting damping term. The derivative $\mathrm{Cmq}$ term representing model rotation around the balance center does not play a role in divergent growth since the frequency of the model-balance mode is $15 \mathrm{~Hz}$ different from sting first mode frequency of $10.1 \mathrm{~Hz}$. The following sections analyze how the boundary layer transition choice impacts CRM sting dynamics in a polar.

\section{A. Fixed Boundary Layer Transition Sting Response in a Polar}

Figure 10, plot (a) shows the raw PM and NF response as a function of angle of attack in a polar for the WB case for warm temperatures, low dynamic pressure at $\mathrm{Re}_{\mathrm{c}}=5$ million. An abrupt increase of response near 6 degrees is visible. This corresponds to the second pitching moment break. Plot (b) shows the sting bending response as a function of angle of attack. Large but stable sting response can be seen during the polar. The sting response up to about 6 degrees suggests a net positive large sting damping for the system. Increased sting response beyond the second pitching moment break indicates a reduction in sting system damping which remains a low positive and fixed boundary layer transition.

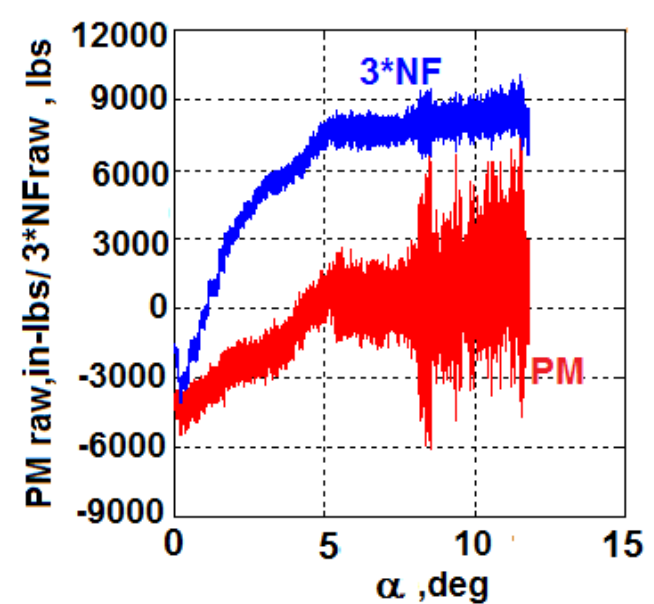

(a)

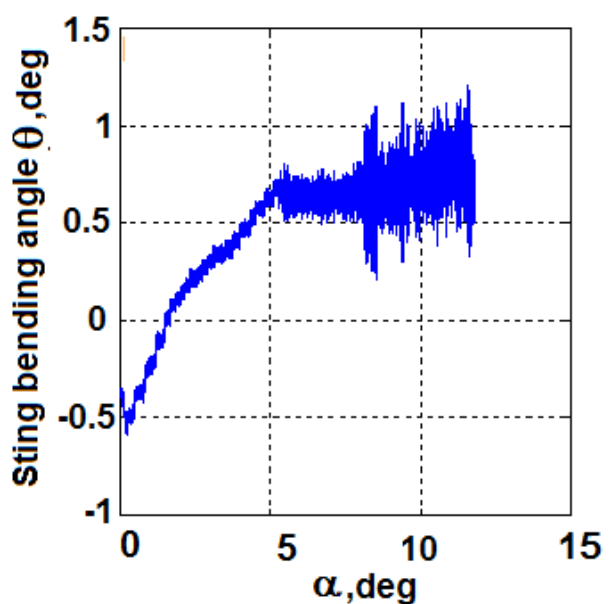

(b)

Figure 10. Sting system response, $W B$ configuration, $M=0.85, R_{c}=5$ million, $T_{t}=120^{\circ} F$.

\section{B. Free Boundary Layer Transition Sting Response in Polars}

Figure 11 shows typical test polars as time plots of load and sting bending for free transition at $\mathrm{Re}_{\mathrm{c}}=19.8$ million for WB and WBT0 configurations. Irrespective of the configuration, the CRM sting system begins divergent oscillations near the second pitching moment break. Plot (a) shows the raw wideband normal force while plot (b) shows the pitching moment. For both WB and WBT0 cases, violent and divergent sting oscillations are seen to occur at a angle of attack of approximately 5.6 degrees. While net sting damping remains positive up to the second pitching moment break, initiation of divergent unstable response beyond the second pitching moment break is due to the net sting damping going negative. The presence of the tail has not modified the sting dynamics. Hence, net negative damping changes for the sting system is a wing induced process effect. 


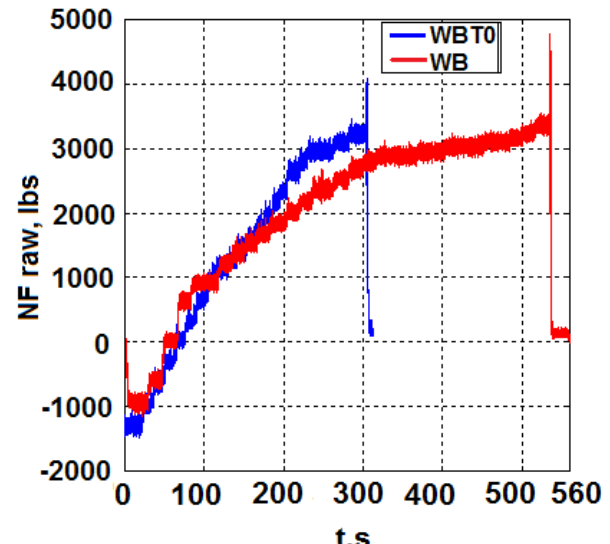

(a)

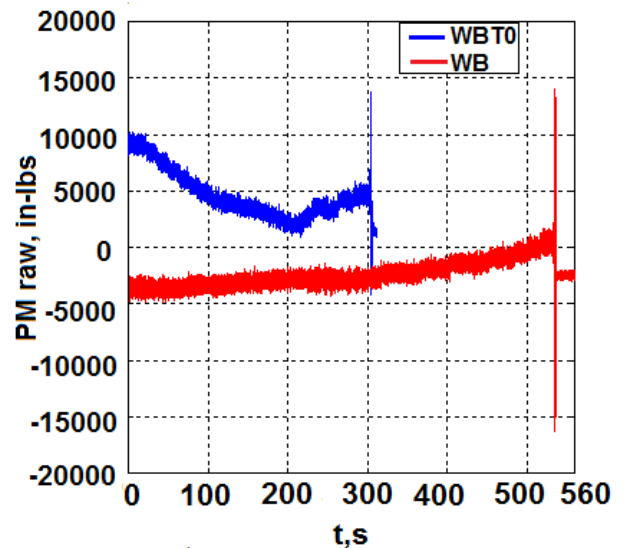

(b)

Figure 11. Sting system response, $M=0.85, R_{c}=19.8$ million.

\section{Center of Pressure Movement in Polars}

In order to analyze the reasons for large negative aerodynamic damping beyond the second pitching moment break, a study of the movement of the Center of Pressure (CP) has been made to see if the CP trajectory and its location when sting damping changes occur has any direct influence on the net sting damping. This is based on slender body theory ${ }^{10}$ which suggests that pitch damping of aerodynamic bodies related to angle of attack rate is a function $f\left(X_{C P}-X_{C G}\right)$ of $\mathrm{CP}$ distance to the sting connection point.

Figure 12 plot (a) shows that at 5 million Reynolds number, the free transition trajectory is $4-8 \%$ aft of fixed transition case through the polar. Plot (b) summarizes the $\mathrm{CP}$ movement for $\mathrm{M}=0.85$ at $\mathrm{Re}_{\mathrm{c}}=5,19.8$ and 30 million as a function of angle of attack for the WB configurations with a different mix of boundary layer transition. While these trajectories differ at low angles of attack, most converge to a single area second moment break, where the onset of damping changes are initiated. Thus, there is no evidence from the plots to indicate that CP movement during a polar influences the negative damping initiation process which is largely controlled by moment break. No WBTi cases are used since net sting dynamics is not influenced by the addition of a tail, as shown in Figure 11.

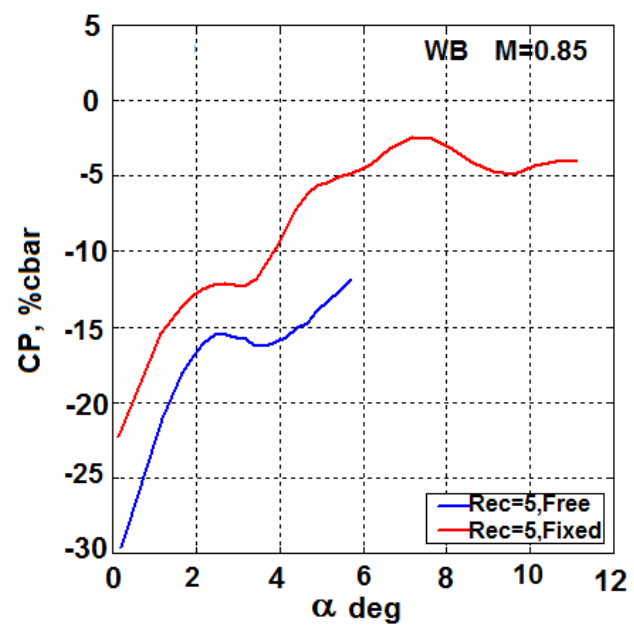

(a)

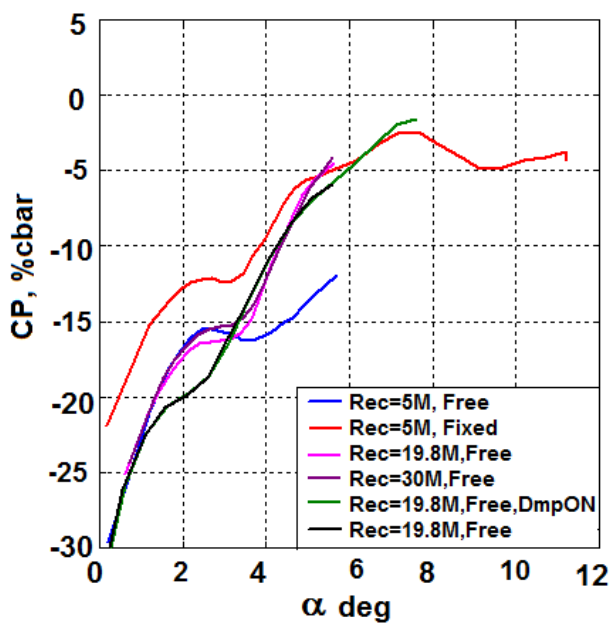

(b)

Figure 12. $C P$ movement, $M=0.85, \operatorname{Re}_{c}=5,19.8$ and 30 million.

\section{Summary Observations}

CRM tests covered Reynolds numbers of 5, 19.8 and 30 million for a Mach $=0.85$ and other Mach numbers ranging from 0.7 to 0.92 . The test set used both fixed and free-boundary layer transition based on Reynolds number covering WB and WBT0 configurations. The CRM sting vibration dynamics can be summarized from analysis of 
the static aerodynamic force-moment data, low bandwidth dynamic balance data and wideband strain data as follows:

1) Wing buffeting starts at the first pitching moment break point in a polar, as evident from dynamic wing root strain data. Buffet is the disturbance driving the sting system longitudinal response beyond the buffet point.

2) Sting dynamic response data from all the CRM tests at $M=0.85$ suggests that aerodynamic pitch damping dynamic derivative induces a rapid reduction in sting damping as the angle of attack approaches the second pitching moment break point.

3) At low Reynolds numbers of $\mathrm{Re}_{\mathrm{c}}=5$ million with fixed transition, the loss of damping near the second moment break is relatively small compared to the net sting system mechanical damping. Hence, net sting damping stays a low positive through angles of attack up to 10-12 degrees with increasing stable buffet response.

4) For high Reynolds number tests of $\mathrm{Re}_{\mathrm{c}}=19.8$ and 30 million with free-boundary layer transition, the loss of damping near the second moment break point is in excess of the sting system mechanical damping and hence sting damping becomes negative. Divergent sting oscillations are encountered as $\alpha$ approaches the second moment break point.

5) The Reynolds number effects contribute to the magnitude of the net sting damping changes beyond the second pitch moment break.

6) Historically, NTF high Reynolds number transonic tests of Boeing 767, 777 and other transport models 6,11 have consistently shown this divergent sting response near the second pitching moment break. This suggests that the pitch damping jump has origins in wing flow transition from laminar to turbulent.

7) Since the ARC 11-foot Transonic Wind Tunnel (TWT) CRM test was only performed at low Reynolds numbers, (i.e. warm temperatures, low dynamic pressure) the test data set did not show any sting divergence episodes in its entire series but the tests saw increased sting response beyond the second moment break point.

\section{Active Sting Damper}

Figure 13 shows the use of high force piezo actuators to create bending moment in the sting for CRM, both in pitch and yaw ${ }^{5}$. To mitigate the sting pitch dynamic instability, it is necessary to actively control one of the negative feedbacks of balance signal measured $\partial \mathrm{PM} / \partial \mathrm{t}$ to sting as a counter moment via piezo devices. The control law used for piezo damper is a simple feedback as described in Eq. (5).

$$
I \frac{d^{2} \theta}{d t^{2}}+\frac{d \theta}{d t}(f-\Sigma /(\partial \theta / \partial t))+k_{g} \frac{\partial P M}{\partial t}+\theta(k-\partial \Sigma / \partial \theta)=0
$$

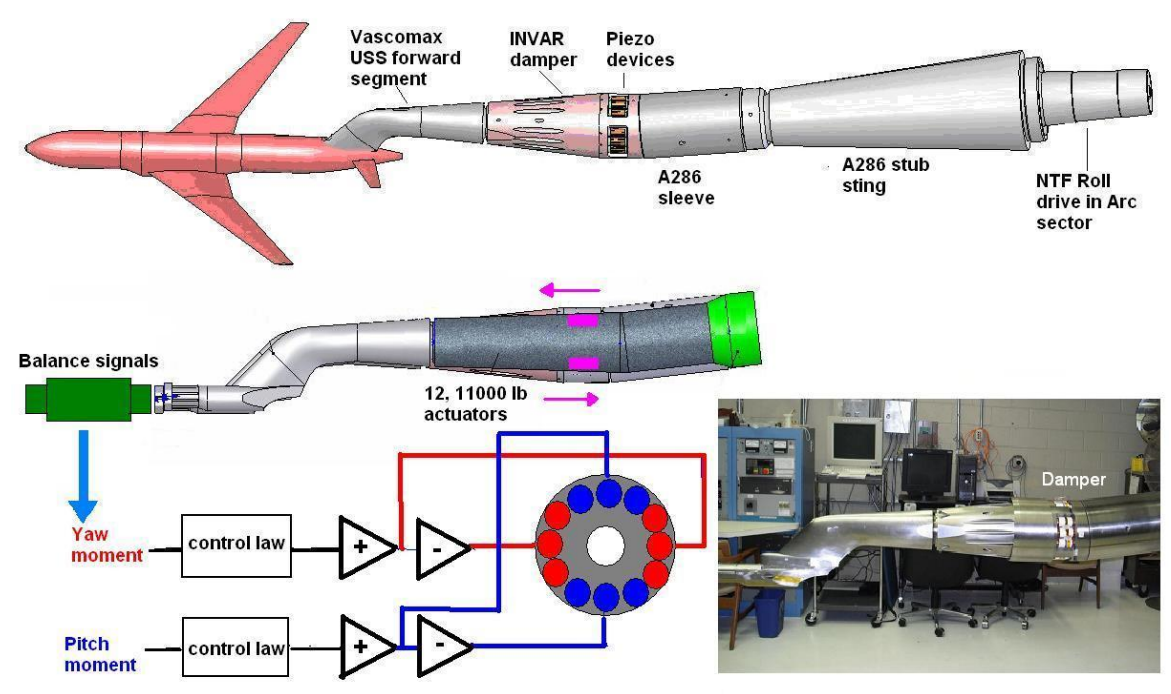

Damper Control Schematic

Figure 13. CRM active damper system with piezo devices. 
The control gain $k_{g}$ provides additional damping to improve sting stability. This control law has been tested for the CRM, Crew Launch Vehicle (CLV) and Pathfinder I models effectively ${ }^{4,5}$. However, its performance is limited by the energy of the piezo device.

In the most recent NTF test, the damper piezo elements were kept warm at $70^{\circ} \mathrm{F}$ using a new heater system during CRM polars at tunnel temperatures of $-250^{\circ} \mathrm{F}$, using nearly $2 \mathrm{~kW}$ power. Figure 14 shows a polar where the damper was able to extend the polar from 5.6 to 7.8 degrees with the damper on compared to the damper off case. In both the damper on and off cases, the sting encountered negative damping with divergent sting oscillations at the end of the test. Plots (a) and (b) show the aerodynamic coefficients as a function of angle of attack with the damper on and off run pair. The damper off polar stops near a shallow break point in the pitching moment plot (a), which when seen as wideband raw moment in plot (c) shows a large moment gradient. Plot (d) shows the sting bending during the two polars and plot (c) shows the wideband raw NF vs. PM with a sharp moment slope reversal for the damper on case near the end of the polar. The damper has been effective in extending the test range at high Reynolds number.

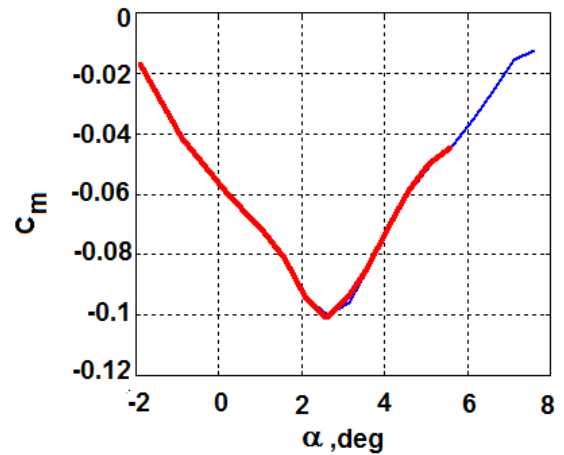

(a)

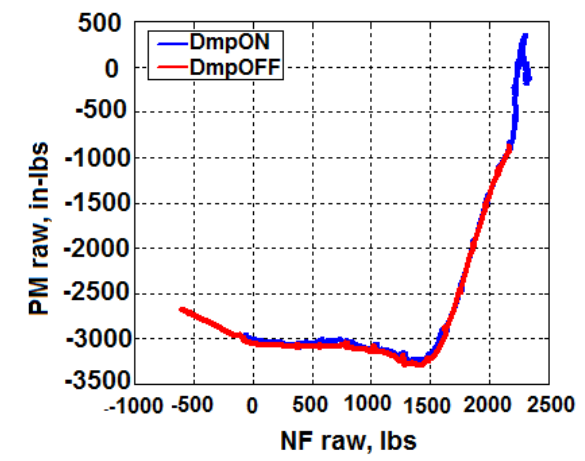

(c)

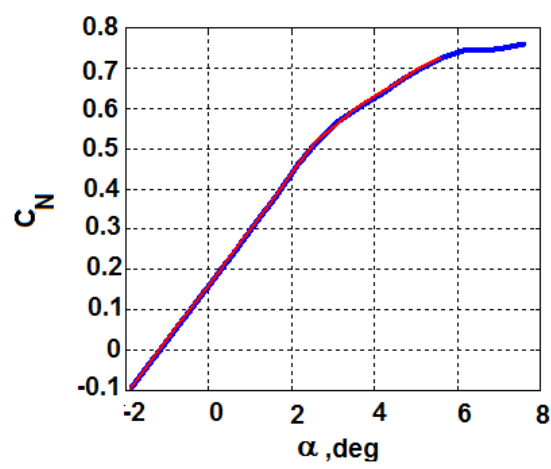

(b)

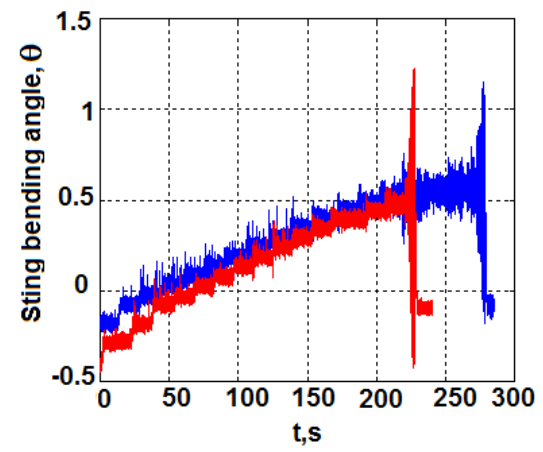

(d)

Figure 14. Free transition active damper performance, $W B$ configuration, $M=0.87, \operatorname{Re}_{c}=19.8$ million, $\mathbf{T}_{\mathbf{t}}=\mathbf{- 2 5 0}{ }^{\circ} \mathbf{F}$.

Figure 15 shows a typical result for the WBT-2 configuration at $\mathrm{Re}_{\mathrm{c}}=5$ million when the test has been extended from about 5.8 degrees to nearly 11 degrees angle of attack by use of the damper. Plots (a) and (b) show the aerodynamic coefficient improvements while plots (c) and (d) show PM and NF during the polar as a function of time. Plot (c) illustrates the lowered damping response beyond the moment break point. Here, also, the loss of damping near the second moment break point is evident in the $\mathrm{C}_{\mathrm{m}}$ plot. 


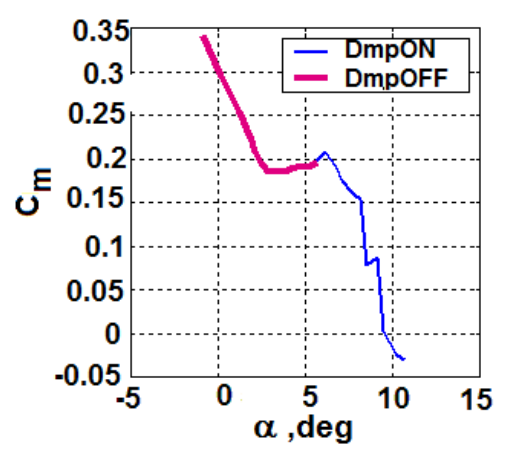

(a)

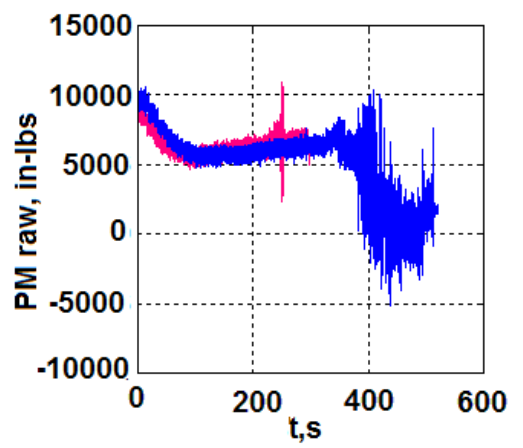

(c)

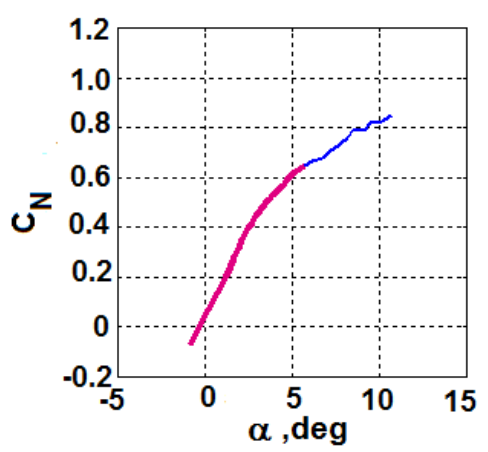

(b)

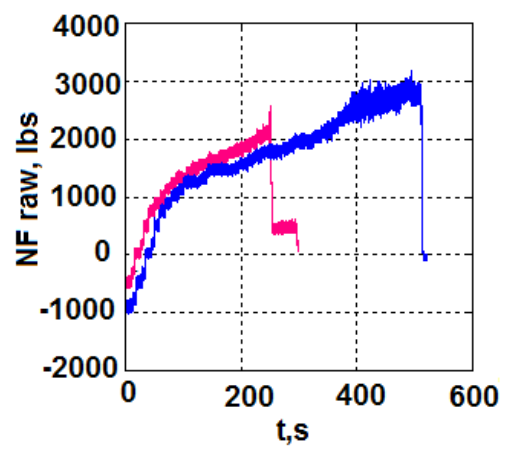

(d)

Figure 15. Fixed transition damper performance, $W B T-2$ configuration, $M=0.87, R_{c}=5$ million, $T_{t}=120 F$.

\section{Discussion of Damper Performance}

The CRM damper has been evaluated at two transonic facilities in three tests using a piezo based sting damper. The damper system was not designed to work at cryogenic temperatures for the first entry at NTF, but was modified by the use of heaters for the most recent test at cryogenic temperatures. Amongst the $\operatorname{Re}_{\mathrm{c}}=5$ million test with fixedtransition using trip dots at ambient temperature, about 40 polars were designed to go to high angle of attack. The active damper did provide reduced buffet response and allowed full angle of attack range testing beyond the second moment break. For $\mathrm{Re}_{\mathrm{c}}=19.8$ and 30 million polars under cryogenic test conditions, (with temperature controlled piezo devices kept at 70F) the damper provided extended angle of attack range for some cases, but not for all test conditions. The damper did work for $\mathrm{M}=0.70$ and 0.87 by extending the test range under cryogenic conditions. Damping power was not adequate to address the sting divergent oscillations testing at $\mathrm{M}=0.85$ for some cases.

The piezoceramic based damper concept does work to mitigate damping issues by adding damping. However, with the present state of the art of piezo device availability, the size to power ratio realizable limits the damping power available in testing the CRM with its complex Mach dependent pitch damping performance. The NTF damper was designed to reduce model dynamics in pitch and yaw. Based on experience from the three tests conducted, yaw damping is not considered a safety critical issue, unlike pitch where divergent oscillations can occur. Hence design of a pitch alone damper would be adequate for a CRM type of model. In the design of the NTF CRM damper, the invar body houses both pitch and yaw control devices. This damper can be upgraded to have tandem piezo devices in pitch to realize twice the damping power for the same number of piezo devices and related hardware by skipping yaw damping control.

\section{Conclusion}

Test data from CRM wind tunnel evaluation in two transonic facilities, over a period of four years, shows that abrupt aerodynamic damping changes occur as the angle of attack approaches the second pitching moment break angle of attack, resulting in reduction of the net sting damping. The magnitude of damping changes are higher for high Reynolds number tests resulting in net negative sting damping and divergent oscillations. The magnitude of damping change is relatively low near the second moment break point for low Reynolds number fixed transition 
tests resulting in increased but stable sting dynamics. The NTF designed piezo active damper adds damping to the sting system. It has overcome sting divergent oscillations during high Reynolds number testing for a limited number of cases and has permitted a larger angle of attack test range at cryogenic temperatures. The NTF active sting damping capability is limited by the piezo device capacitance to volume ratio availability ${ }^{5}$. Active dampers do help in reducing stable buffet response of stings for tests on transport models at transonic speeds for low Reynolds numbers and delaying or suppressing the onset of sting divergent situations for high Reynolds number testing.

\section{References}

${ }^{1}$ Igoe, W.B. and Capone, F.T.; "Reduction of Wind Tunnel Model Vibration by Means of a Tuned Damped Vibration Absorber Installed in a Model”; NASA-TMX-1606, July 1968.

${ }^{2}$ Freymann, R; "Passive and Active Damping Augmentation Systems in the Fields of Structural Dynamics and Acoustics"; AIAA-1989-1196.

${ }^{3}$ Fuykschot, P.H.; "The Use of Friction Springs for Damping Model Vibrations"; National Aerospace Laboratory, NLR, STA Proceedings, April 1999.

${ }^{4}$ S. Balakrishna, D. H. Butler, R. White, \& W. A. Kilgore; “Active Damping of Sting Vibrations in Transonic Wind Tunnel Testing"; AIAA- 2008-0840.

${ }^{5}$ S. Balakrishna, D. H. Butler, Michael J. Acheson, \& E. Richard White; "Design and Performance of an Active Damper for NASA Common Research Model"; AIAA-2011-953, 49 ${ }^{\text {th }}$ AIAA Aerospace Sciences meeting including the New Horizons Forum and Aerospace Exposition, 4-7 January 2011, Orlando, Florida.

${ }^{6}$ C. P. Young, Jr;’'Dynamic Response Characteristics of Two Transport Models Tested in NTF”; NASA CR $191420,1993$.

${ }^{7}$ John C. Vassberg, Mark A. DeHaan, S. Melissa Rivers, Richard A. Wahls; " Development of Common Research Model for Applied CFD Validation Studies"; AIAA-2008-6919.

${ }^{8}$ Vassberg, J. C., Tinoco, E. N., Mani, M., Rider, B., Zickuhr, T., Levy, D. W., Broderson, O. P., Eisfeld, B., Crippa, S., Wahls, R. A., Morrison, J. H., Mavriplis, D. J., Murayama, M., "Summary of the Fourth AIAA CFD Drag Prediction Workshop," AIAA 2010-4547, 28th AIAA Applied Aerodynamics Conference, Chicago, IL, 28 Jun - 1 Jul 2010.

${ }^{9}$ R. W. Clark, \& R. A. Pelkman;" High Reynolds Number Testing of Advanced Transport Wings in the National Transonic Facility"; AIAA-2001-0910.

${ }^{10}$ James E. Danberg, \& Paul Weinacht, “An Approximate Method for Pitch Damping Prediction”, Army Research Laboratory ARL-TR-3007, July 2003.

${ }^{11}$ Clarence P. Young, Dennis W. Hergert, Thomas W. Butler and Fred M. Herring, "Buffet Test in National Transonic Facility", AIAA 92-4032, July 1992. 